\title{
Human Factors Regarding Age in Single Pilot Transitions to Technologically Advanced Aircraft
}

\author{
John A. Kolmos \\ CUNY Aviation Institute at York College
}

\begin{abstract}
The purpose of this research is investigating the relationship between computer simulated instruction and pilot performance in the transition to technologically advanced aircraft. With the advent of computerized glass cockpits in modern aircraft a problem has arisen of the ability of aging pilots and the human factors involved. These pilots for many years have received training on the round instrument gauges and the question is, can they now safely make the transfer to the new cockpit technologies? Studies show a cognitive deficit with pilot's age 40 years and older making transitions to these advanced cockpits. SPSS statistical software will be used to analyze data looking at specifically Spearman's Rank Order Correlation. This non-parametric statistic will be used to compare one group of under age 40 pilots and one group over age 40 pilots and their ability to transfer to more technologically advanced aircraft.
\end{abstract}

\section{Introduction}

With the movement from standard round instrument gauge setups in the cockpits to all glass in the general aviation (GA) community, problems have come up in regards to transitioning from one avionics setup to the other. The problem centers more on the older generation of pilots who may have difficulty with the transition (Rogers, \& Fisk, 1990, p.177) who for years have flown the standard round gauge referred to as the "six-pack".

\section{Purpose}

The purpose of this research is to highlight a problem that is underlying the general aviation community. Up until the 1980s, the biggest change came in putting a nose wheel on small general aviation aircraft. Then came Loran ((LOng RAnge Navigation), and soon after in the 1990s GPS. Change came but at a slow pace, a pace that many pilots were able to adapt too.

No one could have predicted the rapidity of this change, least of all the hundreds of thousands of pilots around the world who will eventually use them. While the manufacturers were able to make a total shift to "glass" in two years, training pilots will take longer, since the more than 200,000 airplanes that exist today without glass cockpits will continue to constitute the majority of the fleet for years to come. 
Glass cockpits give pilots the benefits of situational awareness, redundancy, decrease of pilot workload and large readable displays. The potential risk is the increased mental workload due to the inherently more complex software interface of glass cockpits. Programming the systems can distract a pilot from the primary task of flying the aircraft. There is also some risk of dependency upon the automation. To stay proficient, pilots will need to balance the time they spend hand flying an aircraft versus using the autopilot, so that their skills remain sharp in both areas. These risks are real and relevant, but under stress a pilot will revert to his old habits and this is where major safety concerns come into play with glass cockpits. Pilots, especially older pilots who for perhaps decades have been flying standard instrument gauges, may, in a crisis, perform a task that only deepens the problem or in a state of confusion the situation ends up becoming critical (Hamblin, Gilmore \& Chaparro, 2006). Proper training coupled with a simulation program that would be available for the pilots to practice and become proficient in may be an answer.

\section{Review of Relevant Literature}

\section{Aging}

Aging has been shown to be a set of progressive changes in the physiological and psychological functioning of an individual. Age-related changes are largely continuous and subtle rather than discrete and dramatic (Czaja, 1990). These theories a generally considered a decline in the rate of central processing speed and a reduction in working memory (Salthouse, 1985, 1990) it affects the performance of complex tasks. Seeing that this is a problem with age and the complexities of operating a TAA aircraft, it can then perhaps present itself as a formable problem with aging pilots. Laboratory and simulator studies appear to support this general prediction in the decline of piloting tasks (Morrow \& Leirer, 1997, p. 221). "Research on performance in other domains such as automobile safety suggests that there may be a "U"-shaped relationship between age and performance (Broach, Joseph \& Schroeder, 2003)." For example, Massie, Campbell, and Williams (1995) found that automobile accident risk was greater for younger and older drivers than for drivers aged 25 to 65 . However, changes in performance associated with aging are characterized as much by increased variability between individuals as by a decline in performance (Landy, 1992; Salthouse, 1985, 1990). "These findings in cognitive research and other transportation modes suggest that the longitudinal effects of aging on aviation safety outcomes such as accidents will be relatively subtle rather than dramatic. Changes in outcomes might be best described in terms of a trend across age groups (Broach, Joseph \& Schroeder, 2003, p.9).”

\section{Automation Training, Learning and Older Pilots}

"The fact that statistics indicate that older pilots have more fatal accidents piloting TAA could be a reason for concern. Could the FITS one-size-fits-all training program be inadequate for older pilots (Homko, 2011, p. 15)?" Recent studies about age and learning have shown that even though some cognitive degradation occurs with age, the ability and desire to learn of older people are not significantly different than younger people when the learning is specifically changed to address their slower learning rate and need for positive reinforcement (Broady, Chan, \& Caputi, 2010). Broady, Chan, \& Caputi (2010) showed that the challenges of cognitive losses due to age can be effectively counteracted by recent training and positive experiences. Broady, Chan, \& Caputi (2010) stated in their study that addressed age and attitude toward computers (Homko, 2011). 
"What can be taken from this observation is an under-standing that older people could well be taught to use technology in much the same way as younger people are taught. However, the literature also suggests that at least two additional considerations are necessary in designing computer and technology education for older learners. First, consideration must be given to allow ample time for older people to master new skills. Second, care must be taken to treat any person learning to use technology in a positive manner that makes them feel like they are valued and that success is the expected outcome. While it is true that these two points ought to be considered for all learners, they nonetheless particularly pertain to older users (Homko, 2011, p. 15).” Homko, (2011) states that small electronic information displays that are installed in complex flight management systems need to change their displays to show additional information, and generally leave no visual indication of where the user has navigated to. "Without these positive visual cues, older adults lose partial episodic memory which in turn affects their ability to recall what they have done (Harada, Mori, \& Taniue, 2010)." "The design of IT systems therefore may be hampering the ability of older users'abilities to use and understand the systems. This is supported by the work of Harada, Mori, \& Taniue (2010) who stated: Older adults seemed to have particular difficulties in learning an abstract model or absorbing local rules during the operation of the system itself. That is, it is more difficult for older adults than younger adults to extract an abstract structure while operating and observing a system that is responding to their operations (Homko, 2011, p. 15)."

With the results shown above what are some of the solutions that may be found in the literature to provide guidance on the cognitive learning that pilot's, especially older pilots whose experience is in the conventional aircraft can be utilized effectively? The AOPA (Aircraft Owners and Pilots Association) through the Air Safety Foundation a division of AOPA states "More and better simulation is gradually becoming available to TAA pilots.... Training to use nontraditional avionics using traditional methods is not optimal. Use of CD/DVD and online simulation is a step forward, as is the development of relatively inexpensive simulators for new TAA" (AOPA Air Safety Foundation, 2007). The TAA Safety Study Team in their report of August 22, 2003 states that "Overall TAA training should rely greatly on various levels of simulation, beginning with computer-based part task trainer for each major TAA system on the aircraft, and moving up to an integrated cockpit simulator for scenariobased training" (TAA Safety Study Team, 2003, p.19). "Research shows that computer-based training in conjunction with a desktop flight simulator can improve significantly the speed at which transition pilots acquire knowledge and skill, particularly for glass-cockpit navigation..." (Mitchell, Chappell, Gray, Thurman, \& Quinn, 2001). Looking how the CBI (Computer Based Instruction) is designed and implemented, taking into consideration the age and experience of the pilot will have an important effect on the transfer of learning from conventional to TAA. Suzanne K. Kearns in her book "ELearning in Aviation" states "Clearly, the effectiveness of any e-learning [CBI] course will be directly linked to how the course is designed" (Kearns, 2010, p.28). The point that Kearns makes is important in the fact that how the course is designed and how effective it is in producing the desired results is the starting point for designing a course of study for the older pilot. The results to be looked at would be pilots, especially those 40 years of age and over, which have had many years using conventional avionics, through a properly designed and executed course, making a successful transition to TAA aircraft in a safe manner. The ideal would be to locate and put into use such a design for those pilots looking into transitioning into TAA.

Has the research been looked into for such a course design and what would it consist of? Looking at the Kennedy et al. (2010) article in their concluding remarks it states "Our findings suggest that providing older pilots with focused training in the flight simulator [emphasis added] for situations that can 
carry a high degree of risk in real life, coupled with speed of processing training may be an ideal way to improve older aviators' flight safety" (Kennedy, Taylor, Reade, \& Yesavage, 2010, pp. 496).

\section{Research Methodology}

The research methodology will consist of TAA aircraft in comparisons to traditional cockpit aircraft; it will be a content analysis of NTSB reports on accidents and incidents involving TAA and conventional display aircraft covering a period from March 2002 to November 2008. These are investigations that have been completed by the NTSB and reported closed. These results will then be a complete and accurate data that can then be collected and analyzed. The aircraft NTSB reports involved in this study are listed in the appendix.

\section{NTSB Content Analysis}

All accident data were extracted from the NTSB Aviation Accident Database. Study analyses were limited to accidents involving U.S.-registered aircraft. Aircraft Fleet Involved In Study

Once the list of aircraft was compiled, that information was used to summarize the data and compare accident involvement by cockpit display type. Aircraft selected for the study included the following makes and models of airplanes manufactured between 2002 and 2006.

- Cessna Aircraft Corporation 172

- 182 series

- 206 series

Cirrus Design Corporation • SR20

- SR22

- Diamond Aircraft • DA40

- Lancair/Columbia Aircraft/Cessna Aircraft Company • 300/35039and 400

- Mooney • M20 series

- Piper Aircraft Inc. • PA-28-161

- PA-28-181

- PA-28-201

- PA-32-301 series

- PA-46-350P

- Hawker Beechcraft Corporation • 36 series

A total of 266 aircraft were studied and listed in the Appendix. Of those 100 were of conventional cockpit display and 166 were included in the glass cockpit display. The study sample was further defined to include single-engine, piston-powered airplanes to allow direct comparisons between aircraft of relatively similar operational and performance capability. Data from the NTSB Aviation Accident Database were used, along with the registration information provided by the report, to identify aircraft in each cockpit configuration that were involved in accidents between 2002 and 2008 and to capture the details of those accidents. NTSB accident data include details of the accident event, such as type of occurrence, phase of flight, and environmental conditions; pilot demographics and experience; and accident investigation findings. This data was used to compare the accident experience of the two avionics type and to make statistical comparisons of the accidents each cockpit experienced. 


\section{Analyses}

Summary statistics were calculated to compare the aircraft cockpits on variables such as the number of aircraft, hours flown, usage details, and accidents. For the aircraft in the study sample that had been involved in accidents, comparisons were made between the conventional and glass cockpit groups on the basis of data collected during the accident investigation, including accident occurrences and findings, weather and operational details, and accident pilot demographics and experience. Because the study was targeted at a relatively small set of aircraft, the number of comparisons that could be made between glass cockpit and conventional aircraft as a function of operational and pilot characteristics was limited by the sample sizes (number of accident cases) for each comparison. Statistical tests appropriate to the various accident-related variables were used to determine the extent to which the conventional and glass cockpits differed.

Using SPSS, chi-square statistics were used to compare the two types of cockpits on categorical accident variables such as weather, time of day, and purpose of flight. Mann-Whitney $U$ tests were used to compare differences in continuous variables, including planned flight distance, pilot age, and flight experience. Spearman's Rank Order Correlation was used in comparing pilot age in conventional to glass displays. The following variables were selected for analysis:

Accident flight information

- Accident severity

- Planned length of flight

- Purpose of flight

- Day/night and visual meteorological conditions

- Visual/instrument meteorological conditions

- Instrument/visual flight rules flight plan

- Accident phase of flight and event details

Pilot information

- Number of pilots aboard accident aircraft

- Age at the time of the accident

- Highest certificate level

- Instrument rating

- Flight hours

Accident rates were calculated for comparison with the applicable exposure data, such as number of aircraft or flight hours. Standard error values were included with the following rate comparisons calculated:

- Accidents and fatal accidents per active aircraft

- Accidents and fatal accidents per flight hour

- Accidents and fatal accidents by time of day

- Accidents and fatal accidents by weather condition

- Accidents and fatal accidents by purpose of flight

Accident records for the 2002-2008 period covered by this study provided enough data to make statistically reliable comparisons between the two study groups. A comparison of the list of study aircraft with NTSB records identified 266 total accidents involving the study aircraft between 2002 and 2008, 62 of which resulted in one or more fatal injuries. Of the 266 study accidents, 141 
accidents—23 of them fatal-involved conventionally equipped aircraft. The remaining 125 total accidents and 39 fatal accidents involved glass cockpit aircraft.

\section{Data Analysis}

Statistical comparisons of the 2002 through 2008 accident data, show similar differences in accident severity by cockpit display type. The percentage of accidents resulting in fatality was about twice as high for the glass cockpits as for the conventional displays. Of the 266 accidents involving study aircraft between 2002 and 2008, accidents involving aircraft in the glass cockpit displays were significantly more likely to be fatal: $\chi^{2}(1, \mathrm{~N}=266)=8.216, \mathrm{p}=0.004 .50$

\section{Flight Conditions}

Time of day. The 2002 through 2008 accident data indicate that a higher percentage of accidents involving aircraft in the glass cockpit group occurred at night, but the difference was not statistically significant: $\chi^{2}(1, \mathrm{~N}=266)=3.058, \mathrm{p}=0.080$.

Weather conditions. The 2002 through 2008 accident data indicate that a higher percentage of glass cockpit accidents occurred in IMC. The difference in accident weather conditions was marginally significant: $\chi^{2}(1, \mathrm{~N}=264)=3.639, \mathrm{p}=0.056$.

Filed flight plans. Consistent with the previous results showing that glass cockpit aircraft spent a higher percentage of flight hours in IMC, the aircraft cockpit displays also differed with regard to flight plan filed for the accident flight. Among those accidents during 2002 through 2008 with flight plan information available, pilots in glass cockpits were significantly more likely to have filed an instrument flight (IFR) flight plan for the accident flight: $\chi^{2}(1, \mathrm{~N}=250)=11.718, \mathrm{p}=0.001$.

Purpose of flight. The study aircraft differed noticeably with regard to aircraft usage. The accident flights involving aircraft in the conventional cohort were almost equally split between instructional flights and personal/business flights, while glass cockpit accidents were significantly more likely to involve personal/business flights: $\chi^{2}(1, \mathrm{~N}=258)=31.616, \mathrm{p}<0.001$.

Planned length of flight. Among those accidents for which both point of departure and intended destination were known, the median planned length of accident flights associated with the glass cockpit display was 96 nautical miles (nm), compared to a median of $25 \mathrm{~nm}$ for conventional aircraft flights. Differences in the planned length of study flights for both cockpit displays were evaluated using the Mann-Whitney $U$ test statistic. Results indicated that accident flights involving the glass cockpit display were significantly longer than those for aircraft in the conventional cockpit display (U $=5649.5, \mathrm{~N}$ (conventional) $=140, \mathrm{~N}$ (glass cockpit) $=122, \mathrm{p}<0.001)$. Much of the difference in planned flight distance between the two displays can be attributed to the large percentage of conventional aircraft operating on local or very short flights, versus the percentage of glass cockpit aircraft, which were more likely to be operating on longer flights. Of the 140 conventional aircraft accidents with flight length information, 71 (51 percent) were conducting local flights that were planned to return to the departure airport or very short flights of less than $25 \mathrm{~nm}$. Only 26 percent of glass cockpit accident flights were local or less than $25 \mathrm{~nm}$, but 42 percent of accident flights involving glass cockpit aircraft were planned for more than $150 \mathrm{~nm}$ versus only 16 percent of flights associated with conventional aircraft. 
Phase of flight. In general, aircraft in the glass cockpit displays were involved in a higher percentage of accidents during the in-flight phases from initial climb to approach, while conventional aircraft were involved in higher percentages of accidents during takeoff, landing, and "other," which include taxiing.

Accident Event Type. Glass cockpit aircraft were involved in higher percentages of loss-of-control in flight and collision-with-terrain events, and conventional aircraft were involved in more loss-ofcontrol on ground and hard-landing events. This is consistent with the results of the previous comparison showing more glass cockpit accidents during in-flight phases and more takeoff and landing accidents for the conventional displays.

The higher percentage of collisions with terrain versus all other events for the glass cockpit displays was the only statistically significant difference between the two cohorts in accident events: $\chi^{2}(1, \mathrm{~N}=$ 255) $=3.980, \mathrm{p}=0.046$.

Number of Pilots. Aircraft with conventional cockpits were more likely to have two flight crewmembers aboard than those with glass cockpits, which were more likely to be operated by a single pilot. The difference in the number of flight crew was statistically significant: $\chi^{2}(1, \mathrm{~N}=266)=7.063$, $\mathrm{p}=0.008$. In approximately half of the conventional aircraft cases with two pilots, the second pilot was identified as a flight instructor, which is consistent with the previously presented results indicating that conventional aircraft were more likely to be used for instructional flights.

Pilot Age. Age data were available for 257 of the 266 accident pilots considered in the study. Accident pilots in the glass cockpit cohort ranged in age from 18 to 77, with a median age of 47 . Accident pilots in the conventional cohort ranged in age from 17 to 73, with a median age of 43. Accident pilots flying glass cockpit aircraft were significantly older than those flying conventional aircraft ( $\mathrm{U}=6736.5, \mathrm{~N}$ (conventional) $=139, \mathrm{~N}$ (glass cockpit) $=118, \mathrm{p}=0.014)$. Much of the difference between the conventional and glass cockpit study displays with regard to age can be attributed to differences in the percentage of young pilots. Of the 139 accident pilots in the conventional aircraft cohort whose age was known, 38 (27 percent) were under 30 years old. In contrast, for the glass cockpit cohort, only 14 of the 118 accident pilots (12 percent) for whom age information was available were under 30 years old. 


\section{Conventional accident rate 40 and over}

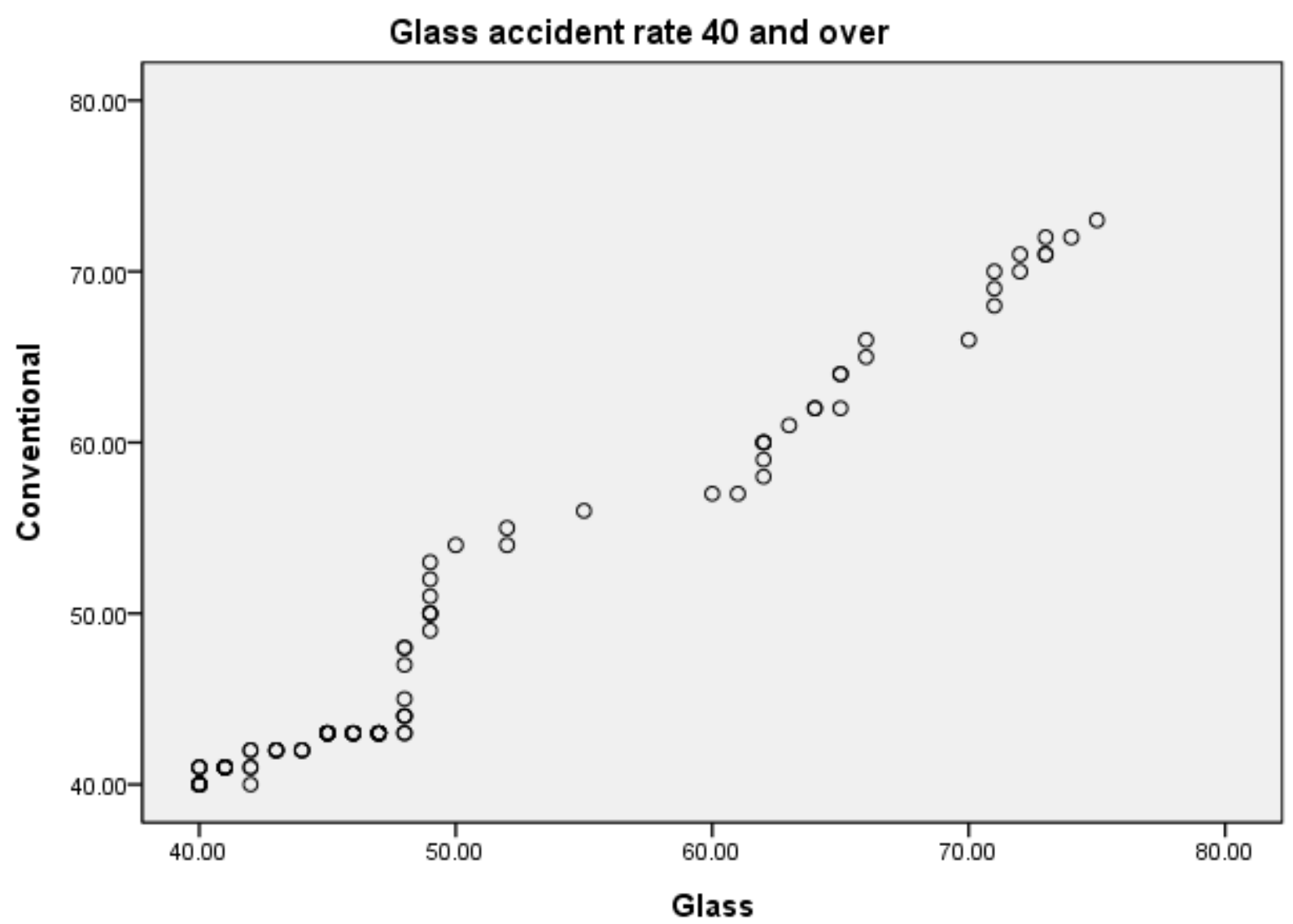

Figure 1. Scatter plot showing age and cockpit orientation between glass and conventional displays

Table 1. Spearman's Rank Order Correlation between Conventional and Glass Cockpits Pilot Certificate Level.

\section{Correlations}

\begin{tabular}{|ll|l|l|}
\hline & & Conventional & Glass \\
\hline Spearman's rho Conventional & Correlation & 1.000 & $.986^{* *}$ \\
& Coefficient & & \\
& Sig. (1-tailed) & & .000 \\
& $\mathrm{~N}$ & 101 & 101 \\
\cline { 2 - 4 } & Correlation & $.986^{* *}$ & 1.000 \\
& Coefficient & & \\
& Sig. (1-tailed) & .000 & 104 \\
& $\mathrm{~N}$ & 101 & 104 \\
\hline
\end{tabular}

**. Correlation is significant at the 0.01 level (1-tailed). 
Of those accident pilots for whom certificate information was available, 26 percent held airline transport pilot (ATP) or commercial certificates, 50 percent held private pilot certificates, and 24 percent held student pilot certificates. Nearly equal proportions of the two display types held commercial or ATP certificates, but the two displays differed significantly with regard to student and private pilot certificates: $\chi^{2}(2, \mathrm{~N}=261)=21.931, \mathrm{p}<0.001$. In comparison, the data concerning the FAA's U.S. civil airman certificate for 2002 through 2008 indicate that an average of approximately 14 percent of active pilots held a student pilot certificate, 38 percent a private pilot certificate, and 43 percent a commercial pilot certificate or ATP.

Pilot Instrument Rating. Approximately 65 percent of accident pilots in the glass cockpit displays were rated for instrument flight, compared to 37 percent of those in the conventional displays. The difference in instrument rating between aircraft displays was statistically significant: $\chi 2(1, \mathrm{~N}=257)=$ 20.828, $\mathrm{p}<0.001$. In comparison, the FAA's U.S. civil airman statistics indicate that, on average, 51 percent of the active pilot population from 2002 to 2008 held an instrument rating.

Pilot flight hours. The most commonly available measures of accident pilot flight experience were total flight hours in all aircraft and total time in the accident aircraft make and model. The total flight time of accident pilots in glass cockpit aircraft ranged from 22 to approximately 25,000 hours, while the total flight time for accident pilots in conventional aircraft ranged from 1 to 23,000 hours. The median number of total flight hours for glass cockpit pilots was higher than the median total flight hours for pilots of conventional aircraft (466 hours and 167 hours, respectively), and accident pilots in the glass cockpit displays had significantly more total flight hours than those in the conventional displays: $\mathrm{U}=5503.0, \mathrm{~N}$ (conventional) $=138, \mathrm{~N}$ (glass cockpit) $=118, \mathrm{p}<0.001$. Flight experience in the accident aircraft make and model for pilots in glass cockpit aircraft ranged from 11 to approximately 1,430 hours and for accident pilots in conventional aircraft, from 1 to approximately 6,200 hours. Median flight experience in make and model for glass cockpit pilots was higher than for those flying conventional aircraft ( 99 hours and 70 hours, respectively). However, the overall distributions of flight time in the accident make/model were not significantly different: $U=6087.5$, $\mathrm{N}($ conventional $)=129, \mathrm{~N}$ (glass cockpit $)=106, \mathrm{p}=0.148$. It is important to note that data concerning flight experience in aircraft make and model made no distinction in cockpit design, so some pilots may have been experienced in the aircraft type while having little experience with the particular cockpit display in the aircraft.

\section{Results}

Accident and fatal accident rates were higher for the glass cockpits in IMC and at night despite the aircraft being flown by pilots with higher levels of certification and more flight experience, and the additional capabilities of glass cockpit displays, which were intended to improve the safety of those flight operations. This study showed similar patterns of accident rates for the study aircraft. Glass cockpit aircraft showed a lower accident rate but a higher fatality rate than conventional cockpit aircraft. Age also showed no real significance between the two, both groups average about the same over age 40 in accident rates. Age did play a role in that glass cockpit aircraft tend to be flown by older and more experienced pilots than conventional cockpit designs. Statistical comparisons of accident characteristics though did identify several variables with distributions significantly different between the conventional and glass cockpit groups, including accident severity, the purpose of the accident flight, and the planned length of flight, the number of pilots, pilot age, certification level, total flight experience and pilot instrument rating. Conventional cockpit aircraft tend to be flown by younger more inexperienced pilots and on instructional flights. These flights would have a tendency not be 
involved in a fatal accident, which historically, instructional flights have had lower fatal accident rates than personal flying.

Although the accident statistics identify a weakness in pilot decision-making, it is unclear why GA pilot training programs fail to teach this skill. The FAA requires pilot instruction in aeronautical decision making but offers minimal guidance to flight instructors of how this should be done. To date, most safety-related initiatives addressing weather-related accidents have consisted of motivational and experiential based approaches (Wiggins \& O'Hare, 2003). However, training programs that identify dangerous behaviors (i.e., scud running) and advise individuals of the dangers of such behavior have little effect (Halpern, 1998, 2000). The absence of transferability of knowledge to real world settings may result from: 1) content (i.e., emphasis on wrong knowledge and/or skills) and 2) pedagogical style (i.e., part-task training versus SBT) as opposed to a more androgynous style approach. If pilot decisionmaking failures were related to one or both of these factors then the primary focus of future research would be to identify the fundamental skills and knowledge a pilot should master and the form that instruction should then be designed and replace what is offered in most flight schools at this time. At present, the literature does not identify which is the primary culprit in failures of GA decision making.

\section{Conclusion}

In the literature review, it was shown that age and pilot effectiveness in cognitive abilities do deteriorate and that in more advanced designs such as TAA aircraft, the effect is even more pronounced. It was also shown in the data analysis of the NTSB reports that pilots overall above the age of 40 in both glass and conventional cockpits are having more problems in aircraft accidents and incidents in comparison to their younger peers. The data also shown that particularly older pilots were having more difficulties in IMC and in what normally is considered a safe segment of a flight, cruise. The literature review and the data has also shown that through a properly designed program and instruction any pilot regardless of age can improve his/her performance to acceptable levels to perform safe and successful flights in transitioning to TAA aircraft. The aviation industry together with the Federal Aviation Administration have come together to develop a systematic program of training for today's technologically advanced aircraft. It is known as the FITS program of study. FITS is the acronym for FAA Industry Training Standards (Summers, Ayers, Connolly \& Robertson, 2007, p.4). Summers et al. (2007) shows the design of the FITS program is to go beyond the traditional training in flight schools to scenario-based training (SBT) "where the instructor introduces real life situations for the development of the pilot. This training is a scenario-based approach to training pilots. It emphasizes the development of critical thinking and flight management skills, rather than solely on traditional maneuver-based skills.

For pilots 40 years and older who have not been exposed to these advanced avionics platforms, a training edge is given through these programs to develop the cognitive skills and processing speed necessary to perform safely in the National Airspace System that can be realized, giving them both a safe and successful flight experience. 


\section{Recommendation}

SBT or scenario based training should be utilized by flight instructors and become part of a regular training syllabus. The FITS program and modules as outlined and presented by the FAA have proven to be effective in the training and transition of pilots to TAA aircraft utilizing scenario based training, similar to what FAR parts 121, and 135 use in their training programs known as LOFT or Line Oriented Flight Training. This exposes pilots to real world scenarios under the guidance of a flight instructor in a controlled environment experience situations where a pilot alone may not be able to handle. In other words the old idea of training to pass a test was perhaps useful in its time, but with advanced aircraft avionics and the complications of the National Airspace System and the coming implementation of Next Gen this is proving not to be enough. Ground based training must also pull away from just the generic to aircraft specific in the realm of the glass cockpit classrooms. Pilots must be able to demonstrate a minimum knowledge of primary aircraft flight instruments and displays in order to be prepared to safely operate aircraft equipped with advanced avionics platforms. There should also be a revision of the airman knowledge tests to include questions regarding electronic flight and navigation displays, including normal operations, limitations, and the interpretation of malfunctions and aircraft attitudes especially for instrument and commercial testing.

\footnotetext{
About the Author

The Author holds a PH. D from Capella University in Educational Psychology with over 1600 hours of flight time in various aircraft with an ATP, CFI, CFII, IGI, AGI and ADX. Also, an Embry-

Riddle Aeronautical University graduate with a Master of Science in Aeronautics with concentrations in human factors and educational technology in aviation and aerospace.
} 


\section{References}

Air Safety Institute. (2010). NALL report. . Retrieved from http://www.aopa.org/asf/publications/10nall.pdf

Adams, C. A., Hwoschansky, P. V., \& Adams, R. J. Langley Research Center, Federal Aviation Administration. (n.d.).Analysis of adverse events in identifying gps human factors issues. Washington, DC: U.S. Government Printing.

Aviation data and statistics. (2011, October 25). Retrieved from http://www.faa.gov/data_research/aviation_data_statistics/

Aviation safety reporting system.(n.d.). Retrieved from http://asrs.arc.nasa.gov/

Breakwell, C and Bajekal, M. (2005) Review of sources and methods to monitor healthy life expectancy. Health Stat Q; 26: 17-22

Broach, D., Joseph, K. M., \& Schroeder, D. J. Civil Aeromedical Institute, Federal Aviation Administration. (2003). Pilot age and accident rates report 4: An analysis of professional atp and commercial pilot accident rates by age. Washington, DC: U.S. Government Printing.

Broady, T., Chan, A., \& Caputi, P. (2010). Comparison of older and younger adults' attitudes towards and abilities with computers: Implications for training and learning. British Journal of Educational Technology , 41 (3), 473-485.

CAP knowledge base [Web log message]. (2005, March 25). Retrieved from http:/ / capnhq.custhelp.com/app/answers/detail/a_id/1588

Casner, S. M. (2003). Learning about cockpit automation: From piston trainer to Jet Transport. NASA, Ames Research Center. Moffit Field: NASA.

Czaja, S. J. (Ed.) (1990). Human factors research needs for an aging population. Washington, DC: National Academy Press.

Federal Aviation Administration, (2008). Aviation instructor's bandbook. U.S. Department of Transportation. Washington, DC.

Federal Aviation Administration (2002). A study of training devices used by flight training organizations. Washington, D.C.: Federal Aviation Administration.

Gerdsmeier, T, Ladkin, P., Loer, K. (1997) Analyzing the cali accident with a web-graph. Bielefield, University. Bielefield Germany. Paper presented at the Human Error and Systems Development Workshop. Glasgow, UK. 
Golaszewski, R. S. (1983). The influence of total flight time, recent flight time and age on pilot accident rates. (Technical Report No.DTRS57-83-P-80750). Bethesda, MD: Acumenics Research and Technology.

Groff, L. (2010). Safety study report: Introduction of glass cockpit avionics into light aircraft quantitative analysis results. NTSB.NTSB.

Guide, P. C., \& Gibson, R. S. (1991). An analytical study of the effects of age and experience on flight safety. Proceedings of the Human Factors and Ergonomics Society 35th annual meeting, 180-184. Santa Monica, CA: HFES.

Halpern, D. F. (1998). Teaching critical thinking for transfer across domains. American Psychologist, 53(4), 449-455.

Halpern, D. F. (2000). Thinking critically about critical thinking: Lessons from cognitive psychology. Paper presented at the ARI Workshop Proceedings, Fort Leavenworth, KS.

Hamblin, C.J., Gilmore, C., \& Chaparro, A. (2006). Learning to fly glass cockpits requires a new cognitive model. Proceedings of the Human Factors and Ergonomics Society 50 th Annual Meeting, 1977-1981.

Harada, E., Mori, K., \& Taniue, N. (2010). Cognitive aging and the usability of IT based equipment: Learning is the key. Japanese Psychological Research, 52 (3), 227-243.

Homko, C. J. (2011). The effects of age and recency of experience on the completion of complex tasks in a technologically advanced aircraft.(Master's thesis, Purdue University), Available from ProQuest. (1501836).

Kay, E. J., Hillman, D. J., Hyland, D. T., Voros, R. S., Harris, R. M., \& Deimler, J. D. (1994). Age 60 rule research, Part III: Consolidated data base experiments final report.(DOT/FAA/AM-92/22). Washington, DC: Federal Aviation Administration Office of Aviation Medicine.

Kearns, S.K. (2010). E-learning in aviation. Burlington, VT: Ashgate Publishing Company.

Kennedy, Q., Taylor, J.L., Reade, G., \& Yesavage, J.A. (2010). Age and expertise effects in aviation decision making and flight control in a flight simulator. Aviation, Space, and Environmental Medicine, 81(5), 489-497

Krey, N. (2007). AOPA Online: Air Safety Foundation - Special Reports. (B. Landsberg, Ed.) Retrieved February 20, 2010, from AOPA Online: Air Safety Foundation: http://www.aopa.org/asf/publications/topics/TAA2007.pdf

Landy, F. J. (1992). Alternatives to chronological age in determining standards of suitability for public safety jobs. Volume I: Technical report. University Park, PA: Center for Applied Behavioral Sciences. 
Li, G., \& Baker, S. P. (1994).Prior crash and violation records of pilots in commuter and air taxi crashes: A case-control study. Aviation, Space, and Environmental Medicine, 65, 979985.

Li, G., Grabowski, J. G., Baker, S. P., \& Rebok, G. W. (2006). Pilot error in air carrier accidents: Does age matter. Aviation, Space, and Environmental Medicine, 77(7), 737-741.

Massie, D. L., Campbell, K. L., \& Williams, A. F. (1995). Traffic accident involvement rates by driver age and gender. Accident Analysis and Prevention, 27, 73-87

Mitchell, C.M., Chappell, A.R., Gray, W.M., Thurman, D.A., \& Quinn, A.B. (2001). Intelligent tutors for aviation automation mitigating the problem. Proceedings of the Human Factors and Ergonomics society 45th Annual Meeting - 2001, 200-2004.

Morrow, D., \& Leirer, V. (1997). Aging, pilot performance, and expertise. In A. D. Fisk \& W. A. Rogers (Eds.).Handbook of human factors and the older adult (pp. 199 - 230). San Diego, CA: Academic Press.

Mortimer, R. G. (1991). Some factors associated with pilot age in general aviation crashes. Proceedings of the 6th International Symposium on Aviation Psychology, (pp.770-775). Columbus, OH: The Ohio State University.

National Aeronautics and Space Administration (n.d.).Aviation safety reporting system.(n.d.). Retrieved from http://asrs.arc.nasa.gov/

NTSB.(n.d.).Accident database and synopses. Retrieved from http://www.ntsb.gov/aviationquery/index.aspx

Office of Technology Assessment.(1990). Medical risk assessment and the age 60 rule for airline pilots. (Report submitted the Subcommittee on Investigations and Oversight, Committee on Public Works and Transportation, U.S. House of Representatives). Washington, DC: Author.

O'Hare, D., \& Owen, D. (2001). The 'where' and the 'why' of cross-country vfr crashes: database and simulation analyses. Proceedings of the Human Factors and Ergonomics Society 45 th Annual Meeting-2001, 78-81.

Reason, J. (1997).Managing the risks of organizational accidents. Hants, England: Ashgate Publishing Limited.

Rebok, G. W., Grabowski, J. G., Baker, S. P., Lamb, M. W., Willoughby, S., \& Li, G. (1999). Pilot age and performance as factors in aviation crashes. Poster presented at the Annual Meeting of the American Psychological Association, Boston, MA.

Rogers, W.A., \& Fisk, A.D. (1990).Identifying the learning capabilities of older adults: associative and priority learning. Proceedings of the Human Factors Society 34th Annual Meeting1990 (pp. 173-177). 
Salthouse, T. (1985).A theory of cognitive aging. New York: North-Holland.

Salthouse, T. (1990). Influence of experience on age differences in cognitive functioning. Human Factors, 32, 551-569.

Summers, M., Ayers, F., Connolly, T., \& Robertson, C. (2007). Managing risk through scenario based training, single pilot resource management, and learner centered grading. Retrieved from http://www.faa.gov/training_testing/training/fits/guidance/media/RM_thorugh_SBT.pdf

TAA Safety Study Team Federal Aviation Administration, (2003, August 22). General aviation technically advanced aircraft FAA-industry safety study. Retrieved from http://www.faa.gov/training_testing/training/fits/research/media/TAA\%20Final\%20Rep ort.pdf

Taylor, H. L., Talleur, D. A., Bradshaw, G. L., Emanuel Jr., T. W., Rantanen, E., Hulin, C. L., et al. (2003). Effectiveness of personal computers to meet recency of experience requirements (No DOT/FAA/AM-03/3). Savoy, Illinois: University of Illinois at UrbanaChampaign

Wiener, E. L. (1993). CRM in high-tech cockpits. E. L. Wiener, B. G. Kanki, \&R. L. Helmreich, Cockpit Resource Management (pp. 199-229). Academic Press.

Wiggins, M. W., \& O'Hare, D. (2003). Expert and novice pilot perceptions of static in-flight images of weather. International Journal of Aviation Psychology, 13(2), 173-187. 